\title{
Prevalence and determinants of hoarseness in school-aged children
}

\author{
Ahmed Alrahim ${ }^{1}$, Askar Alshaibani ${ }^{1}$, Saad Algarni $^{2}$, Abdulmalik Alsaed ${ }^{1}$, Amal \\ Alghamdi $^{2}$, Salma Alsharhan ${ }^{1}$, and Mohammad Albar ${ }^{1}$ \\ ${ }^{1}$ Imam Abdulrahman Bin Faisal University King Fahd Hospital of the University \\ ${ }^{2}$ Imam Abdulrahman Bin Faisal University
}

January 7, 2021

\begin{abstract}
BACKGROUND: Hoarseness in school-aged children may affect their educational achievement and interfere with their communication and social skills development. The global prevalence of hoarseness in school-aged children ranges between $6 \%$ and 23\%. OBJECTIVE: Measure the prevalence of hoarseness among school-aged children and identify its associated factors. DESIGN: Cross-sectional questionnaire-based survey. SETTING: Randomly selected primary and early childhood schools in Saudi Arabia. PATIENTS AND METHODS: Data were collected using a questionnaire completed by the children's parents, which included sociodemographic aspects, health and related comorbidities, history of frequent crying during, history of letter pronunciation problems and stuttering, history of vocal fold surgery, the Reflux Symptom Index (RSI), and Children's Voice Handicap Index-10 for parents (CVHI-10-P). MAIN OUTCOME MEASURES: Determinants of hoarseness were investigated using the chi-square test, Fisher exact test, and adjusted and unadjusted logistic regression models SAMPLE SIZE: 428 children RESULTS: The mean age of the study children was $9.05 \pm 2.15$ years, of whom $69.40 \%$ were male. The rate of hoarseness in the participants was $7.5 \%, 9.90 \%$ were female and $6.40 \%$ were male. Hoarseness was found to be significantly associated with a history of excessive crying in infancy $(12.24 \%, \mathrm{x} 2=7.54, \mathrm{p}=0.006)$, letter pronunciation issues, especially ' $\mathrm{R}$ ' and ' $\mathrm{S}$ ' ( $13.56 \%$, $\mathrm{x} 2=8.71, \mathrm{p}=0.003)$, stuttering $(16.39 \%, \mathrm{x} 2=8.08, \mathrm{p}=0.004)$, and those with a previous history of hoarseness $(\mathrm{p}=0.023)$. In addition, having symptoms of gastrointestinal reflux increased the risk of hoarseness by four times $(\mathrm{OR}=4.77,95 \% \mathrm{CI}=2.171$, 10.51) after adjustment for age and gender. CONCLUSIONS: Hoarseness in children may be underestimated as it may reflect the presence of speech problems (i.e., letter articulation and stuttering) in addition to the presence of laryngopharyngeal reflux. Hoarseness was assumed on the basis of parental complaints. Therefore, further research with diagnosis based on clinical assessment is needed to understand the magnitude of the hoarseness and its consequences
\end{abstract}

\section{Prevalence and determinants of hoarseness in school-aged children}

Authors : Ahmed A. Alrahim ${ }^{1}$, MD; Askar Alshaibani ${ }^{2}$, MD; Saad A. Algarni ${ }^{2}$, MD; Abdulmalik Alsaed ${ }^{1}$, MD; Amal A. Alghamdi ${ }^{3}$, MD, MSc, PhD; Salma Alsharhan ${ }^{1}$, MD; Mohammad H. AlBar ${ }^{1}$,MD

${ }^{1}$ ENT department, King Fahad Hospital of the University, College of Medicine, Imam Abdulrahman bin Faisal University, Dammam, Saudi Arabia

${ }^{2}$ College of Medicine, Imam Abdulrahman bin Faisal University, Dammam, Saudi Arabia

3 Department of Family and Community Medicine, College of Medicine, Imam Abdulrahman bin Faisal University, Dammam, Saudi Arabia

\section{Corresponding Author:}

Ahmed Abdulrahman Alrahim, M.D

Address: ENT department, King Fahad Hospital of the University, College of Medicine, Imam Abdulrahman bin Faisal University, Dammam, Saudi Arabia 
Phone: +966555805616

E-mail: aaalrahim@iau.edu.sa

\title{
Disclaimer:
}

While the advice and information in this article were believed to be true and accurate at the time of going to press, the authors accept any legal responsibility for the content of this manuscript.

\begin{abstract}
:
BACKGROUND: Hoarseness in school-aged children may affect their educational achievement and interfere with their communication and social skills development. The global prevalence of hoarseness in school-aged children ranges between $6 \%$ and $23 \%$.
\end{abstract}

OBJECTIVE : Measure the prevalence of hoarseness among school-aged children and identify its associated factors.

DESIGN: Cross-sectional questionnaire-based survey.

SETTING: Randomly selected primary and early childhood schools from private and governmental sectors in the Eastern Province, Saudi Arabia.

PATIENTS AND METHODS: Data were collected using a questionnaire completed by the children's parents, which included sociodemographic aspects, health and related comorbidities, history of frequent crying during infancy, history of letter pronunciation problems and stuttering, history of vocal fold surgery, the Reflux Symptom Index (RSI), and Children's Voice Handicap Index-10 for parents (CVHI-10-P).

MAIN OUTCOME MEASURES: Determinants of hoarseness were investigated using the chi-square test, Fisher exact test, and adjusted and unadjusted logistic regression models

SAMPLE SIZE: 428 children

RESULTS: The mean age of the study children was $9.05 \pm 2.15$ years, of whom $69.40 \%$ were male. The rate of hoarseness in the participants was $7.5 \%, 9.90 \%$ were female and $6.40 \%$ were male. Hoarseness was found to be significantly associated with a history of excessive crying in infancy $\left(12.24 \%, \mathrm{x}^{2}=7.54, \mathrm{p}=0.006\right)$, letter pronunciation issues, especially ' $\mathrm{R}$ ' and ' $\mathrm{S}$ ' $\left(13.56 \%, \mathrm{x}^{2}=8.71, \mathrm{p}=0.003\right)$, stuttering $\left(16.39 \%, \mathrm{x}^{2}=8.08\right.$, $\mathrm{p}=0.004)$, and those with a previous history of hoarseness $(\mathrm{p}=0.023)$. In addition, having symptoms of gastrointestinal reflux increased the risk of hoarseness by four times $(\mathrm{OR}=4.77,95 \% \mathrm{CI}=2.171,10.51)$ after adjustment for age and gender.

CONCLUSIONS: Hoarseness in children may be underestimated as it may reflect the presence of speech problems (i.e., letter articulation and stuttering) in addition to the presence of laryngopharyngeal reflux. Hoarseness was assumed on the basis of parental complaints. Therefore, further research with diagnosis based on clinical assessment is needed to understand the magnitude of the hoarseness problem and its consequences in children.

\section{Keywords: Hoarseness, Voice disorders, School, Children}

\section{What is already known about this topic?}

The global prevalence of hoarseness in school-aged children ranges between $6 \%$ and $23 \%$. Voice disorders in children negatively affect their personality and educational progress, which eventually affect their normal developmental milestones. There are many different factors that lead to hoarseness in children including personal, environmental, psychosocial, and genetics factors.

\section{What does this article add?}

To our knowledge, our study is the first large-scale study that has examined prevalence of hoarseness in school-aged children in Saudi Arabia and investigated its related risk factors. 


\section{INTRODUCTION:}

Hoarseness or dysphonia is characterized by altered vocal quality, pitch, loudness, or vocal effort that impairs communication or reduces voice-related quality of life (QOL). ${ }^{1}$ It can affect all age groups and all genders with a prevalence of approximately $29.9 \%$ and is more common among professional voice users such as singers or teachers. ${ }^{2,3}$ Children are also susceptible to develop hoarseness, with a prevalence ranging from $6 \%$ to $23 \%$ among school-aged children. ${ }^{4}$ It has been estimated that $2-4 \%$ of children with voice problems have never consulted a speech language pathologist for management. ${ }^{5}$ Voice disorders in children might negatively affect their personality and educational progress, which can eventually affect their normal developmental milestones. ${ }^{6}$ Thus, it is important to address and manage this problem as early as possible. In adults, the prevalence of hoarseness is higher in females than in males. ${ }^{3}$ However, the opposite has been observed in children, with a higher prevalence among males than in females. ${ }^{7}$ There are many different factors that lead to hoarseness, such as personal, environmental, psychosocial, and genetics factors. ${ }^{8,9}$ Depending on the etiology, voice disorders in children can be treated medically, surgically, or through voice therapy. ${ }^{6}$

The Voice Handicap index (VHI) is one of the most common validated tools used among clinicians to subjectively measure multiple aspects of voice disorders including the physical, functional, and emotional aspects. ${ }^{10}$ The VHI was developed by Jacobson et al in 1997, with a set of 30 items; in 2004, a simplified, less time-consuming, and easier-to-use version of a 10-item questionnaire was developed by Rosen et al, and it has been adopted and translated into many languages. ${ }^{11,12}$ The VHI is mainly used in adult patients and cannot be used in children as it is difficult for them to understand it. Therefore, many different tools, such as the Pediatric Voice Handicap Index (pVHI), Children's Voice Handicap Index-10 (CVHI-10), and Children's Voice Handicap Index-10 for parents (CVHI-10-P), were developed from the VHI and were validated for use in children. ${ }^{13} 14{ }^{15}$ The CVHI-10-P is a set of 10 validated items used to assess the parents' perspective toward their children's voice to help clinicians to better assess voice disorders in children.

The Reflux Symptom Index (RSI) is one of the tools available to subjectively assess the Laryngopharyngeal reflux (LPR) severity that was developed and validated by Belafsky in $2002 .{ }^{16}$ It has been found that up to $50 \%$ of adult patients with voice disorders also have LPR symptoms. ${ }^{17}$ Block et al found that $47 \%$ of children who presented with a main complaint of hoarseness were diagnosed with LPR. ${ }^{18}$ This study aimed to measure the prevalence of hoarseness among school-aged children and to establish possible associated risk factors.

\section{PATIENTS AND METHODS:}

This is a cross-sectional questionnaire-based survey conducted randomly in 21 early childhood and primary schools from the private and government sectors from April 2019 to November 2019 in the Eastern Province of Saudi Arabia. The questionnaire was answered by 428 participants, who were the parent of a child attending one of the randomly chosen schools. These parents were approached by their child's class teacher, who was also chosen randomly amongst her/his selected school, by sending them a link to an online self-completed questionnaire using the class e-mail group. The data collection lasted for a month and the response rate was around $50 \%$. The survey was designed on the basis of previously published literature as well as our clinical observations. ${ }^{15,16,19}$

The questionnaire was completed by one of the parents of the chosen class children and covered the following aspects: sociodemographic features, health and related comorbidities and medications, household pets (presence vs absence), number of children in the family and child birth order (first vs middle vs last), number of classes the child attends per day, number of students per class, missing days from schools due to voice problems (yes vs no), usual degree of child's voice tone (low vs moderate vs high), child's participation in school activities or sport exercises that require a loud voice (yes vs no), family history of voice disorders (yes vs no), past history of frequent excessive crying during infancy (yes vs no), history of letter pronunciation problems (yes vs no), stuttering (yes vs no), history of intubation (yes vs no), history of having a cold or recurrent cough in the past 2 years (yes vs no), history of hearing problems (yes vs no), parent smoking status (smoker vs non-smoker vs ex-smoker), history of vocal fold surgery (yes vs no), Reflux Symptom 
Index (RSI), ${ }^{16}$ and Children's Voice Handicap Index-10 for parents (CVHI-10-P). ${ }^{15}$ An RSI with a score $>13$ indicates a subjective diagnosis of LPR and a CVHI-10-P with a score $>11$ indicates a subjective diagnosis of voice disorders.

This study was approved by the Institutional Review Board (IRB) of King Fahd Hospital (IRB-2019-01-271) and the parents' consents were taken in advance and at the end of the questionnaire. We attached an optional question for children with voice disorders who wanted to seek medical care in our otolaryngology department for further management.

Data was entered and factors associated with hoarseness were investigated and analyzed using the Chi-square test, Fisher's exact test, and adjusted and unadjusted logistic regression models using SPSS software version 20 (IBM, Chicago, Illinois, USA). For statistical analysis, p $<0.05$ was considered statistically significant.

\section{RESULTS:}

Table 1 shows the participant's background characteristics. The total number of participants was 428 and the majority $(90.9 \%, \mathrm{n}=389)$ were in primary school, whilst the remainder were in kindergarten $(9.1 \%, \mathrm{n}$ $=39$ ). The mean age of the participants was 9.05 years (standard deviation $(\mathrm{SD})=2.15$ ), of whom $69.40 \%$ $(\mathrm{n}=297)$ were males and $30.6 \%(\mathrm{n}=131)$ were females. Almost $60 \%$ of the participants $(\mathrm{n}=260)$ had 2 to 4 siblings and $34 \%(\mathrm{n}=147)$ had more than 5 siblings. Half of the children were a middle child $(50.9 \%$, $\mathrm{n}=218)$ and a third of them were firstborns $(33.2 \%, \mathrm{n}=142)$; the majority of the children lived with both their parents $(93.2 \%, \mathrm{n}=399)$.

The prevalence of hoarseness among our participants was $7.5 \%$, of which $9.90 \%$ were females and $6.40 \%$ were males. Table 2 shows that $85 \%(\mathrm{n}=366)$ of the participants frequently used a medium to high pitch voice tone. With regards to the voice problem indicators as measured using the Children's Voice Handicap Index-10 for parents, approximately $4.2 \%(\mathrm{n}=18)$ of parents reported that their child had severe hoarseness, $19.9 \%(\mathrm{n}=85)$ reported that their child's voice was difficult to hear, $13.3 \%(\mathrm{n}=57)$ claimed that their child's voice reduced their school outcome, and $11.2 \%(\mathrm{n}=48)$ of parents claimed that their child's voice made them feel inferior to other children.

As seen in Table 3, the rate and risk of hoarseness were significantly higher in children with a history of excessive crying in infancy (odds ratio $(\mathrm{OR})=2.733,95 \%$ confidence interval $(\mathrm{CI})=1.315$ to 5.683 ), a previous history of hoarseness ( $\mathrm{OR}=2.315,95 \% \mathrm{CI}=1.109$ to 4.832$)$, letter articulation problems, especially ' $\mathrm{R}$ ' and ' $\mathrm{S}$ ' $(\mathrm{OR}=2.969,95 \% \mathrm{CI}=1.421$ to 6.204$)$, stuttering $(\mathrm{OR}=3.213,95 \% \mathrm{CI}=1.428$ to 7.228 . In addition, only two children had previous vocal cord surgery, one of whom had hoarseness.

In regard to the RSI, the average score of all participants was $5.08(\mathrm{SD}=6.34$, minimum $=0$, maximum $=$ $40)$ and the number of participants with an RSI $>13$ was $55(12.9 \%)$. In addition, it was found that the risk of hoarseness increased by four times if the RSI score was $>13$ (i.e. a child was possibly having LPR; OR = $4.77,95 \% \mathrm{CI}=2.17$ to 10.51 ).

\section{DISCUSSION:}

This study aimed to measure the rate of hoarseness among school-aged children. In our study, we found that the prevalence of hoarseness was $7.5 \%$, which is within the same range reported in the literature as $6-23 \% .^{4}$ Dobres et al found in their study on the description of laryngeal pathologies in children with a sample size of 731 that the prevalence was more in males than in females, which was similar to the findings of Kallvik et al in their study on the prevalence of hoarseness in school-aged children with a sample size of $217 .^{7,19}$ Children have a lower amount of elastin and their vocal fold is less stable than in adults who have a significant amount of elastin and collagen which provide more stability and provide the elastic propriety of the vocal folds. Consequently, the vocal fold of children with recurrent voice misuse vibrate more forcefully because of a lack of elastic proprieties, putting them at a higher risk of injury compared to adults, ${ }^{20} 21{ }^{22}$ hence that might account for the high rate of hoarseness in children.

In our study there was not a significant difference in the prevalence of hoarseness according to gender, 
though it was found to be higher in females than in males, which is similar to the prevalence in adults. ${ }^{3}$ It is suggested that the impact of gender on the voice is not significant in early childhood until the period when each gender acquires his or her specific voice tone and pattern as well as the social specific behavior of each gender. ${ }^{19,23,24}$

Concerning the possible risk factors of hoarseness, we found that a history of excessive crying during infancy was a possible factor associated with current hoarseness in our study. Kallvik et al reported a similar finding, whereby a history of heavy voice use during infancy was significantly associated with current voice quality, especially among females. ${ }^{19}$ Moreover, we found that a previous history of hoarseness was significantly associated with current hoarseness. Continued voice misuse in children and lack of education in voice therapy might keep them at high risk of repeated voice disorders. In our study, we found that letter articulation problems, or what is known as phonation disorder, was an associated risk factor of hoarseness in children. The exact reason is unknown but it might be due to the fact that a child with a problem in letter articulation will try hard to articulate the letters correctly, putting his voice in a repeated tension along with a misuse of his voice, eventually leading to voice disorders. Furthermore, letter articulation issues might be a symptom of hidden underlying structural abnormalities such as a cleft palate or neurological disorders. ${ }^{25}$ Additionally, in our study we found that stuttering was another possible risk factor for hoarseness. Stuttering or dysfluency is a type of speech disorder that prevents an individual from speaking fluently. As a result, a stutterer will repeat words, sounds, sentences, or take sudden involuntary breaks, which might lead to abnormal physical and emotional behaviors as the speaker struggles to end a particular sentence. ${ }^{26}$ Stuttering can be developmental, which is the most common type, or acquired secondary to brain injury or emotional trauma. ${ }^{27,28}$ Salihović et al studied voice characteristics in stuttering children in their case-control experimental study and they found that the abnormal functioning of the larynx and high muscular tension as well as subglottic pressure with lack of coordination and control of respiratory muscles and laryngeal muscles all lead to voice disorders. ${ }^{29}$ Children who stutter were found to be at high risk of developing social anxiety, low self-esteem, and a decreased quality of life in the future. ${ }^{30,31}$ In our study, parents of children with hoarseness reported that their child's educational outcome was affected by hoarseness; they also reported that their child felt inferior to other children and they were bothered by their voices. In this regard, early diagnosis of stuttering is important as it can have very promising outcomes with early interventions. ${ }^{32}$ Hence, early identification and referral to a speech language pathologist is required and suggested to parents.

The LPR is an inflammatory reaction caused by the backflow of gastric acid, which leads to laryngitis and pharyngitis. ${ }^{33}$ We found that those having symptoms suggesting LPR (RSI > 13) had a four-fold increased risk of hoarseness. Block et al found in their study on the role of LPR in children with hoarseness in a sample size of 337 participants that $47 \%$ of the children who presented with the main complaint of hoarseness were diagnosed with LPR and $68 \%$ of patients showed improvement in hoarseness after initiating anti-reflux management. ${ }^{18}$ Moreover, Gumpert et al found in their study that $90 \%$ of children with hoarseness had endoscopic signs of LPR. ${ }^{34}$ Carr et al described the endoscopic findings of LPR in their study as: lingual tonsillar hyperplasia, postglottic edema, and arytenoid edema. ${ }^{35}$ Remarkably, the study of Block et al found that $48 \%$ of patients diagnosed with LPR had no cough or throat clearing, which are the most common symptoms seen in children with LPR. Hence, hoarseness in children is an important key to diagnosing LPR. ${ }^{18}$ Most studies in the literature correlate the endoscopic finding of LPR with subjective complaints of hoarseness i.e. there is no acoustic voice analysis for hoarseness with an objective assessment. However, Niedzielska et al conducted a study on 11 participants in whom reflux disease was confirmed with pH-metric assessment in the esophagus as well as objective voice measurements with lupolaryngoscopy, stroboscopy, and acoustic voice analysis (jitter, shimmer, harmonic/noise ratio, and phonation time). ${ }^{36}$ They confirmed the correlation between an inflammatory changed larynx and voice disorders.

To our knowledge, our study is the first large-scale study that has examined hoarseness in school-aged children in Saudi Arabia and investigated its related risk factors. However, our study had some limitations, including the subjective nature of the tools used (RSI and CVHI-10-P) and the lack of appropriate objective clinical and endoscopic evaluations of the larynx and head and neck region to confirm the diagnosis. Furthermore, one cannot solely depend on RSI for the diagnosis of LPR and more appropriate diagnostic tools such as an 
assessment of the patient's pH levels are needed. ${ }^{37}$ However, clinical assessment was offered to the children of interested parents for further evaluation of their child's voice, but these findings were not included in the current study. Using a cross-sectional design limited the ability to identify the temporal sequences of events, thus causality of identified risk factors could not be established, especially considering the retrospective nature of the questionnaire and the possibility of recall bias and measurement error. However, due to the aim of covering a large sample of schools $(n=21)$ in the eastern province of the Kingdom, parents were contacted by their child's class teacher via an online self-completed questionnaire that, unfortunately, resulted in a limited response rate from the parents, and consequently a possibility of selection bias. However, the resulting prevalence and risk estimations of associated factors of hoarseness in our study were comparable to those reported in the literature and therefore our results could be considered feasible.

In fact, the limited response rate might indicate the possibility of a low level of parental awareness regarding voice disorders in children and the need for further parental education to raise their awareness in the future.

\section{Conclusions:}

Hoarseness in children may be underestimated as it may reflect both the presence of speech problems (i.e., letter articulation and stuttering) and the presence of laryngopharyngeal reflux (LPR). In this study, hoarseness was assumed on the basis of parental complaints, hence further research with diagnoses based on clinical assessment is needed to understand the magnitude of the hoarseness problem and its consequences in children.

\section{References:}

1. Schwartz SR, Cohen SM, Dailey SH, et al. Clinical practice guideline: hoarseness (dysphonia). Otolaryngol Head Neck Surg. 2009;141(3)(suppl 2):S1-S31. DOI: 10.1016/j.otohns.2009.06.744.

2. Roy N, Merrill RM, Thibeault S, Parsa RA, Gray SD, Smith EM. Prevalence of voice disorders in teachers and the general population. J Speech Lang Hear Res. 2004;47(2):281-93. DOI: 10.1044/10924388(2004/023).

3. Roy N, Merrill RM, Gray SD, Smith EM. Voice disorders in the general population: prevalence, risk factors, and occupational impact. Laryngoscope. 2005;115(11):1988-95. DOI: 10.1097/01.mlg.0000179174.32345.41.

4. Maddern BR, Campbell TF, Stool S. Pediatric voice disorders. Otolaryngol Clin North Am. 1991;24(5):1125-40.

5. Kahane JC, Mayo R. The need for aggressive pursuit of healthy childhood voices. Lang Speech Hear Serv Sch. 1989;20(1):102-7. DOI: 10.1044/0161-1461.2001.102.

6. Verduyckt I, Remacle M, Jamart J, Benderitter C, Morsomme D. Voice-related complaints in the pediatric population. J Voice. 2011;25(3):373-80. DOI: 10.1016/j.jvoice.2009.11.008.

7. Dobres R, Lee L, Stemple JC, Kummer AW, Kretschmer LW. Description of laryngeal pathologies in children evaluated by otolaryngologists. J Speech Hear Disord. 1990;55(3):526-32. DOI: 10.1044/jshd.5503.526.

8. Vilkman E. Occupational safety and health aspects of voice and speech professions. Folia Phoniatr Logop. 2004;56(4):220-53. DOI: 10.1159/000078344.

9. Simberg S, Santtila P, Soveri A, Varjonen M, Sala E, Kenneth Sandnabba N. Exploring genetic and environmental effects in dysphonia: a twin study. J Speech Lang Hear Res. 2009;52:153-63. DOI: 10.1044/10924388).

10. Jacobson BH, Johnson A, Grywalski C, et al. The voice handicap index (VHI): development and validation. Am J Speech Lang Pathol. 1997;6(3):66-70. DOI: 10.1044/1058-0360.0603.66.

11. Rosen CA, Lee AS, Osborne J, Zullo T, Murry T. Development and validation of the voice handicap index-10. Laryngoscope. 2004;114(9):1549-56. DOI: 10.1097/00005537-200409000-00009. 
12. Núñez-Batalla F, Corte-Santos P, Señaris-González B, Llorente-Pendás JL, Górriz-Gil C, Suárez-Nieto C. Adaptación y validación del índice de incapacidad vocal (VHI-30) y su versión abreviada (VHI-10) al español. Acta Otorrinolaringol Esp. 2007;58(9):386-92. DOI: 10.1016/S0001-6519(07)74954-3.

13. Zur KB, Cotton S, Kelchner L, Baker S, Weinrich B, Lee L. Pediatric Voice Handicap Index (pVHI): a new tool for evaluating pediatric dysphonia. Int J Pediatr Otorhinolaryngol. 2007;71(1):77-82. DOI: 10.1016/j.ijporl.2006.09.004.

14. Ricci-Maccarini A, De Maio V, Murry T, Schindler A. Development and validation of the children's voice handicap index-10 (CVHI-10). J Voice. 2013;27(2):258.e23-8. DOI: 10.1016/j.jvoice.2012.10.006.

15. Ricci-Maccarini A, De Maio V, Murry T, Schindler A. Development and validation of the children's voice handicap index-10 for parents. J Voice. 2016;30(1):120-6. DOI: 10.1016/j.jvoice.2014.10.004.

16. Belafsky PC, Postma GN, Koufman JA. Validity and reliability of the reflux symptom index (RSI). J Voice. 2002;16(2):274-7. DOI: 10.1016/S0892-1997(02)00097-8.

17. Koufman JA, Amin MR, Panetti M. Prevalence of reflux in 113 consecutive patients with laryngeal and voice disorders. Otolaryngol Head Neck Surg. 2000;123(4):385-8. DOI: 10.1067/mhn.2000.109935.

18. Block BB, Brodsky L. Hoarseness in children: the role of laryngopharyngeal reflux. Int J Pediatr Otorhinolaryngol. 2007;71(9):1361-9. DOI: 10.1016/j.ijporl.2006.10.029.

19. Kallvik E, Lindström E, Holmqvist S, Lindman J, Simberg S. Prevalence of hoarseness in school-aged children. J Voice. 2015;29(2):260.e1-260.19. DOI: 10.1016/j.jvoice.2013.08.019.

20. Chan RW, Fu M, Young L, Tirunagari N. Relative contributions of collagen and elastin to elasticity of the vocal fold under tension. Ann Biomed Eng. 2007;35(8):1471-83. DOI: 10.1007/s10439-007-9314-x.

21. Hammond TH, Gray SD, Butler J, Zhou R, Hammond E. Age- and gender-related elastin distribution changes in human vocal folds. Otolaryngol Head Neck Surg. 1998;119(4):314-22. DOI: 10.1016/S01945998(98)70071-3.

22. Moore J, Thibeault S. Insights into the role of elastin in vocal fold health and disease. J Voice. 2012;26(3):269-75. DOI: 10.1016/j.jvoice.2011.05.003.

23. Duff MC, Proctor A, Yairi E. Prevalence of voice disorders in African American and European American preschoolers. J Voice. 2004;18(3):348-53. DOI: 10.1016/j.jvoice.2003.12.009.

24. Ferrand CT, Bloom RL. Gender differences in children's intonational patterns. J Voice. 1996;10(3):284-91. DOI: $10.1016 / \mathrm{s} 0892-1997(96) 80009-9$.

25. Gray SD, Smith ME, Schneider H. Voice disorders in children. Pediatr Clin North Am. 1996;43(6):135784. DOI: 10.1016/S0031-3955(05)70523-X.

26. Conture EG. Stuttering: its nature, diagnosis, and treatment. xx ed. London: Pearson; 2001.

27. Büchel C, Sommer M. What causes stuttering? PLoS Biol. 2004;2(2):E46. DOI: 10.1371/journal.pbio.0020046.

28. Theys C, van Wieringen A, Sunaert S, Thijs V, De Nil LF. A one year prospective study of neurogenic stuttering following stroke: Incidence and co-occurring disorders. J Commun Disord. 2011;44(6):678-87. DOI: 10.1016/j.jcomdis.2011.06.001.

29. Salihović N, Junuzović-Žunić L, Ibrahimagić A, Beganović L. Characteristics of voice in stuttering children. Acta Med Sal. 2009;38(2):67-75. DOI: 10.5457/ams.55.09.

30. Erickson S, Block S. The social and communication impact of stuttering on adolescents and their families. J Fluency Disord. 2013;38(4):311-24. DOI: 10.1016/j.jfludis.2013.09.003. 
31. Iverach L, Rapee RM. Social anxiety disorder and stuttering: current status and future directions. J Fluency Disord. 2014;40:69-82. DOI: 10.1016/j.jfludis.2013.08.003.

32. Weir E, Bianchet S. Developmental dysfluency: early intervention is key. CMAJ. 2004;170(12):1790-1. DOI: $10.1503 /$ cmaj.1040733.

33. Ford CN. Evaluation and management of laryngopharyngeal reflux. JAMA. 2005;294(12):1534-40. DOI: 10.1001/jama.294.12.1534.

34. Gumpert L, Kalach N, Dupont C, Contencin P. Hoarseness and gastroesophageal reflux in children. J Laryngol Otol. 1998;112(1):49-54. DOI: 10.1017/s002221510013988x.

35. Carr MM, Nagy ML, Pizzuto MP, Poje CP, Brodsky LS. Correlation of findings at direct laryngoscopy and bronchoscopy with gastroesophageal reflux disease in children: a prospective study. Arch Otolaryngol Head Neck Surg. 2001;127(4):369-74. DOI: 10.1001/archotol.127.4.369.

36. Niedzielska G, Wroczek-Glijer E, Toman D. Voice disorders in children with gastroesophageal reflux disease. Otolaryngol Pol. 2000;54(1):67-8.

37. Katz PO. Ambulatory esophageal and hypopharyngeal $\mathrm{pH}$ monitoring in patients with hoarseness. Am J Gastroenterol. 1990;85(1):38-40.

Table 1. Background sociodemographic data $(\mathrm{n}=428)$

\begin{tabular}{llll}
\hline & & Number & \% \\
\hline Age, years & {$[?] 5$} & 28 & 6.5 \\
& $6-9$ & 179 & 41.8 \\
Gender & {$[?] 10$} & 221 & 51.6 \\
Number of siblings & Male & 297 & 69.4 \\
& Female & 131 & 30.6 \\
Child's birth order & $2-4$ & 21 & 4.9 \\
& {$[?] 5$} & 260 & 60.7 \\
Child lives with & 1 & 147 & 34.3 \\
& $2-4$ & 142 & 33.2 \\
Level of education & {$[?] 5$} & 218 & 50.9 \\
& Both parents & 68 & 15.9 \\
& One parent & 399 & 93.2 \\
& Relatives & 24 & 5.6 \\
& Kindergarten & 5 & 1.2 \\
& Primary school & 39 & 9.1 \\
\end{tabular}

Table 2. The distribution of voice hoarseness indictors as measured using the Children's Voice Handicap Index-10 for parents

\begin{tabular}{llll}
\hline Items & Categories & $\mathbf{n}$ & $\mathbf{\%}$ \\
\hline Voice tone & Screaming & 37 & 8.6 \\
& High & 139 & 32.5 \\
& Medium & 227 & 53.0 \\
How severe is the hoarseness? & Low & 25 & 5.8 \\
& Severe & 18 & 4.2 \\
& Moderate & 120 & 28.0 \\
& Mild & 117 & 27.3
\end{tabular}




\begin{tabular}{llll}
\hline Items & Categories & $\mathbf{n}$ & $\mathbf{\%}$ \\
\hline Which part of the day does hoarseness occur? & Morning & 102 & 23.8 \\
& Noon & 28 & 6.5 \\
& Afternoon & 69 & 16.1 \\
& Night & 38 & 8.9 \\
People have difficulty hearing my child because of his voice & No & 343 & 80.1 \\
& Yes & 85 & 19.9 \\
& No & 287 & 67.1 \\
People have difficulty understanding my child in a noisy room & Yes & 141 & 32.9 \\
& No & 384 & 89.7 \\
The voice difficulties of my child prevent him to stay with people & Yes & 44 & 10.3 \\
& No & 390 & 91.1 \\
My child feels left out of conversations because of his voice & Yes & 38 & 8.9 \\
& No & 371 & 86.7 \\
The voice difficulties of my child reduce his school outcome & Yes & 57 & 13.3 \\
& No & 350 & 81.8 \\
My child feels he has to strain to produce voice & Yes & 78 & 18.2 \\
& No & 231 & 54.0 \\
The voice of my child is not light & Yes & 197 & 46.0 \\
& No & 342 & 79.9 \\
The voice problem of my child upsets him & Yes & 86 & 20.1 \\
& No & 380 & 88.8 \\
The voice of my child makes him feel inferior to other children or other boys & Yes & 48 & 11.2 \\
& No & 356 & 83.2 \\
People ask me "What's wrong with the voice of your child?" & Yes & 72 & 16.8 \\
&
\end{tabular}

*Yes indicates those who answered the question with 1 (sometimes), 2 (many times), or 3 (always). These were combined together as Yes.

*No indicates those who answered the question with 0 (never).

Table 3. Distribution of risk factors of hoarseness and the estimated risk of hoarseness in relation to these risk factors

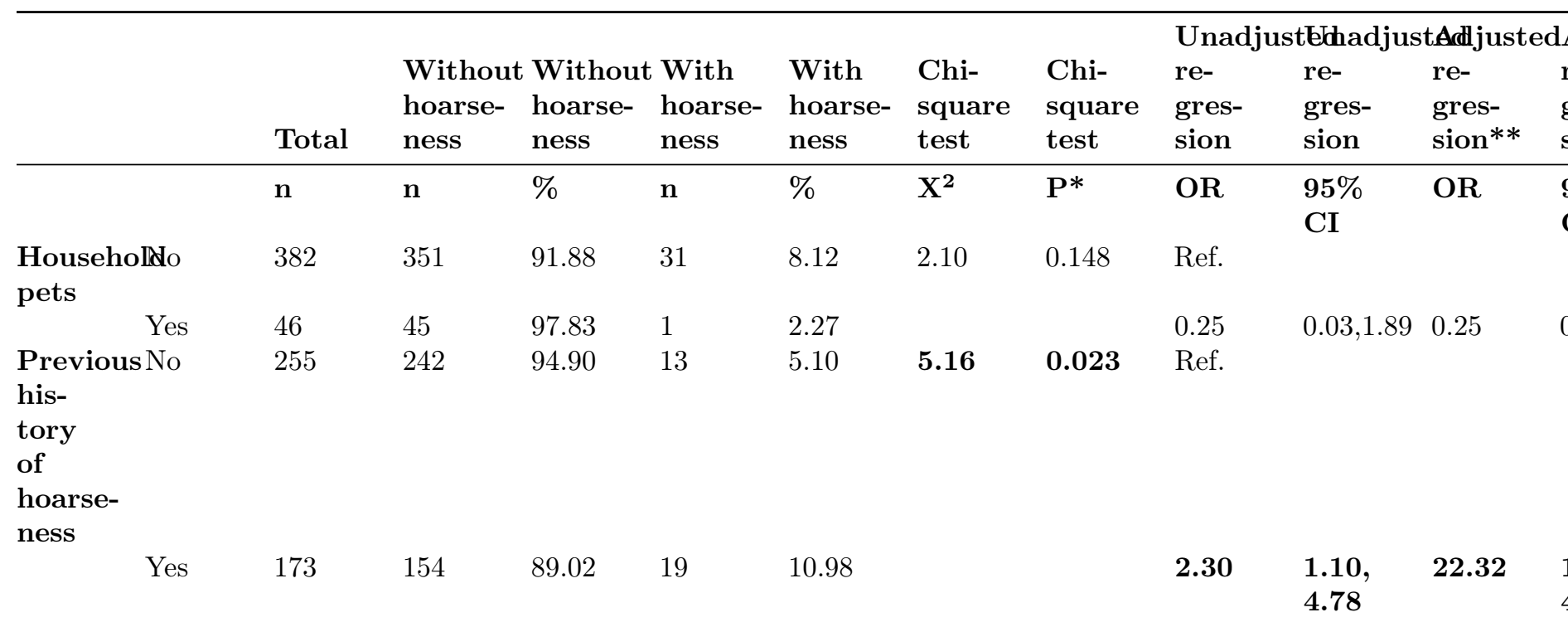




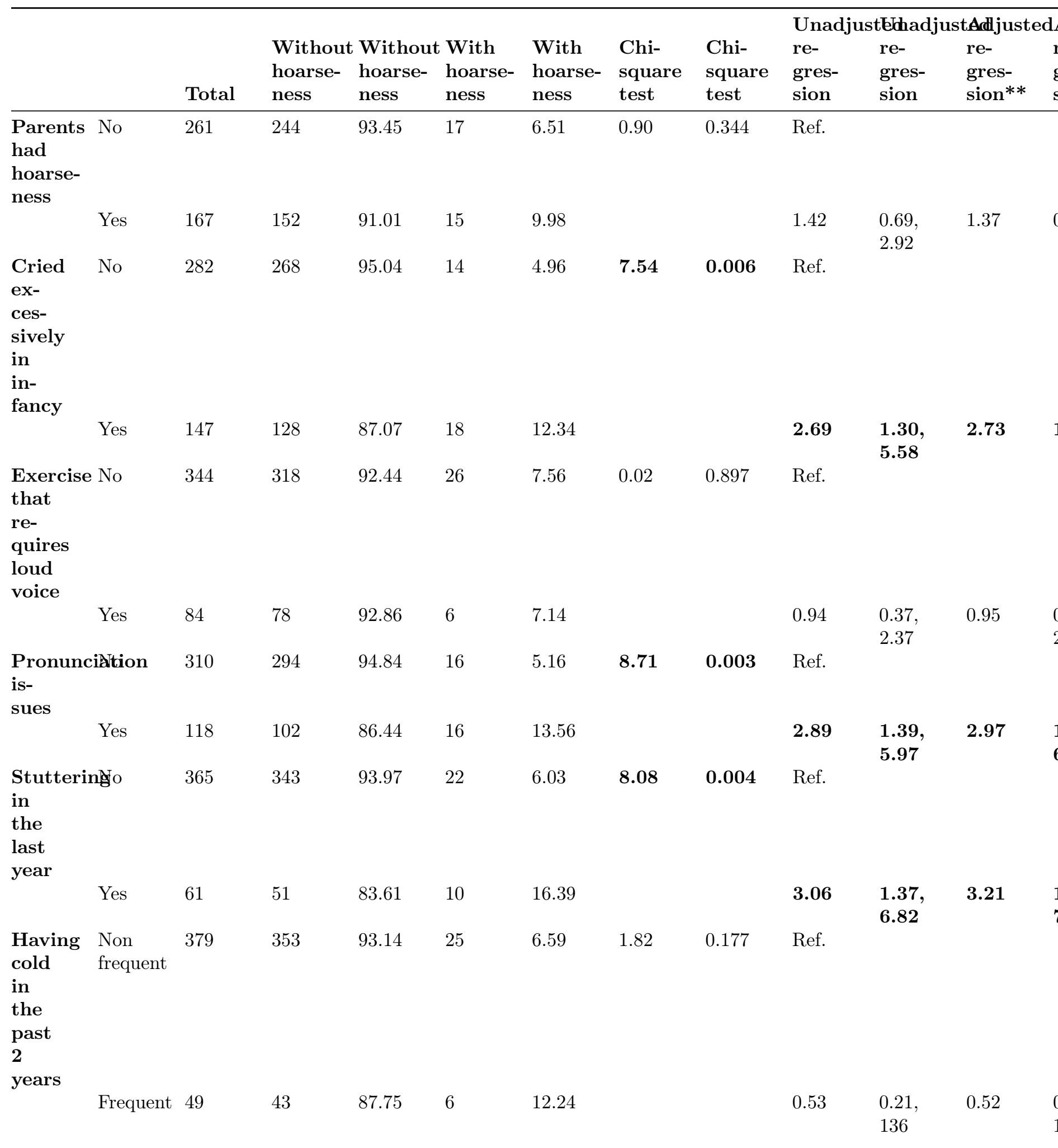




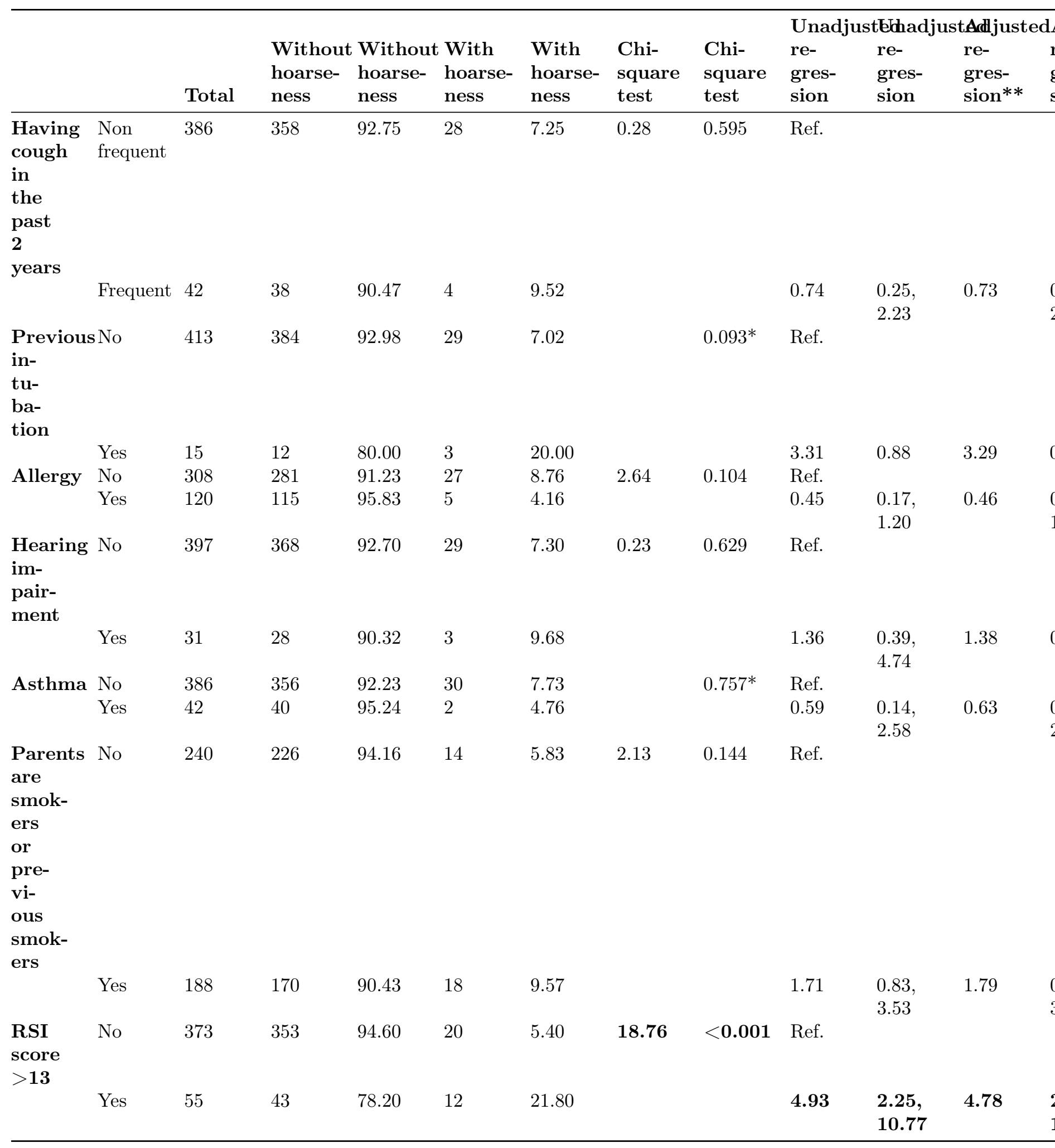

\footnotetext{
** adjusted for age and gender. ${ }^{*} \mathrm{p}$ value was from Fisher exact test. Bold font indicates a statistically
} 
significant result $\mathrm{p}<0.05 . \quad(\mathrm{OR})=$ odds ratio, $(\mathrm{CI})=$ confidence interval, $\left(\mathbf{X}^{2}\right)=$ Chi-square test, $(\mathrm{p})=$ p-value 